\title{
Extraction of Virgin Coconut (Cocos nucifera) Oil Using Supercritical Fluid Carbon Dioxide
}

\author{
Mohd Azizi Che Yunusa ${ }^{*}$, Muhammad Naim Rozaka, Lee Nian-Yiana, Muhammad Syafiq Hazwan Ruslanª, Siti Hamidah Mohd-Setapara, \\ Muhammad Abbas Ahmad Zaini ${ }^{a}$ \\ ${ }^{a}$ Centre of Lipid Engineering and Applied Research (CLEAR), c/o Faculty of Chemical Engineering, Universiti Teknologi Malaysia, 81310 UTM, Johor Bahru, \\ Johor, Malaysia
}

*Corresponding author: azizi@cheme.utm.my

\section{Article history}

Received :1 October 2013

Received in revised form :

23 January 2014

Accepted 27 January 2014

Graphical abstract

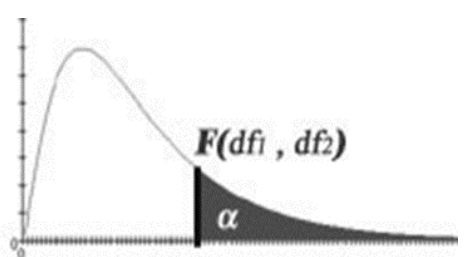

\section{Abstract}

Bioactive compound is an important component in health care to a majority of the world's population Virgin Coconut (Cocos nucifera) oil is used in Southeast Asia for treating various diseases and is wellknown of its rich nutrients. In this study, supercritical fluid extraction (SFE), an environmental friendly technique was used to extract the interest compounds from crude virgin coconut. The extracted virgin coconut oil is free from organic solvent and safe to be consumed. This is because the solvent used in the extraction process is carbon dioxide which is inert and no solvent residue inside the extracted oil. The layout of the experiment was developed via Statistica 8.0 using the Box-Behnken experimental design model. The oil yield, antioxidant activity and total phenolic content were calculated while the comparison of the experimental results and the statistical data was done using response surface methodology (RSM). Therefore, the optimum conditions of temperature and pressure for the extraction of virgin coconut oil was obtained through the statistical study which is $47^{\circ} \mathrm{C}$ and $20 \mathrm{MPa}$ respectively.

Keywords: Cocos nucifera; supercritical fluid extraction; response surface methodology

\subsection{INTRODUCTION}

The coconut oil obtained from dried coconut and copra has no fragrance or taste due to the refining process while virgin coconut oil (VCO) extracted from fresh coconut flesh has taste and fragrance of coconut [1]. The VCO is known as a natural source of medium chain triglycerides (MCTs) which have been reported that fasting plasma triglyceride levels, insulin resistance, inflammatory response as well as body weight management [2]. According to the study by Nevin and Rajamhan [3], the antioxidant activity of VCO is superior to the coconut oil extracted from copra and groundnut oil because VCO is being processed without employing thermal treatment.

Supercritical carbon dioxide $\left(\mathrm{SC}-\mathrm{CO}_{2}\right)$ had been used as the alternative technique to extract the VCO in order to enhance the properties of the extracted VCO. This is because supercritical fluid has relatively low critical temperature $\left(31.1^{\circ} \mathrm{C}\right)$ and critical pressure (73 bar) allows extraction processes to operate near ambient temperature [4]. The low viscosity and high diffusivity of supercritical fluid also cause the mass transfer favorable. Furthermore, carbon dioxide $\left(\mathrm{CO}_{2}\right)$ used as the solvent in this study left no residue in the extracted VCO and this solvent is non-toxic. Hence, the extracted VCO is safe to be consumed and suitable to be applied in food industries.
In this work, the effect of temperature and pressure on the extraction of VCO, antioxidant activity and total phenolic content were studied. The optimization of the extraction conditions was evaluated using statistical method, response surface methodology (RSM) which introduced by G. E. P. Box and K. B. Wilson in 1957 explores the relationships between several explanatory variables and one or more response variables. In addition, the analysis of variance (ANOVA) to examine the significance of the model by using $\mathrm{F}$ tests with $90 \%$ confidence level.

\subsection{EXPERIMENTAL}

\subsection{Raw Materials}

The coconut was Malaysia origin obtained from a local source. The coconut was grated; moisture content was reduced from $50 \%$ to $3 \%$ with sun drying. This was to avoid the clogging of the capillary restrictor due to the water frozen caused by Joule-Thomson effect in the expansion valve. The dried sample was sieved with the average size of $0.424 \mathrm{~mm}$ to $1.5 \mathrm{~mm}$ and was used as the extraction sample. 


\subsection{Extraction of Virgin Coconut Oil (VCO) Using} Supercritical Carbon Dioxide (SC-CO $\left.{ }_{2}\right)$

The experiment was performed with a set of laboratory scale supercritical extraction. The system consists of Supercritical 24 fluid extractor (SSI, State College Pennsylvania, US), a carbon dioxide cylinder, programmable back pressure regulator (Model BP-2080, JASCO, Japan) and constant flow pump which is designed to be reliable component wherever a constant flow must be maintained. Figure 1 shows the schematic diagram of the supercritical carbon dioxide which used for extraction.

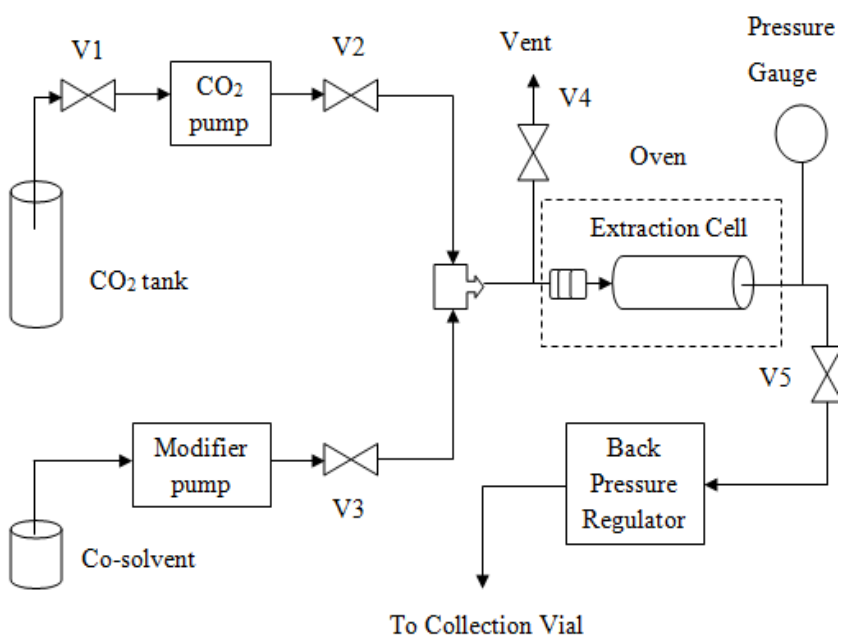

Figure 1 The schematic diagram of supercritical fluid extraction using carbon dioxide as solvent

The extraction process was the semi-batch process with the continuous flow of the carbon dioxide and the flow rate was set at $3 \mathrm{ml} / \mathrm{min}$. As mentioned in section 2.1 ; the coconut crude sample had been grated into coconut powder. The coconut powder is charged into the extractor along with the carbon dioxide. The parameters studied for the supercritical fluid extraction of virgin coconut oil as shown in the Table 1.

Table 1 Parameters studied for supercritical carbon dioxide extraction of virgin coconut oil

\begin{tabular}{ccc}
\hline Variables & Unit & Range \\
\hline Temperature, $\mathrm{X}$ & ${ }^{\circ} \mathrm{C}$ & $45 \leq \mathrm{X} \leq 70$ \\
Pressure, $\mathrm{Y}$ & $\mathrm{MPa}$ & $15 \leq \mathrm{Y} \leq 25$ \\
\hline
\end{tabular}

The oil yield was calculated using the following Equation (1):

Oil Yield $(\%)=\frac{m_{1}}{m_{0}} \times 100 \%$

where $m_{1}$ is mass of the extract in gram and $m_{0}$ is mass of sample in gram.

\subsection{Determination of Antioxidant Activity}

The 2, 2-Diphenyl-1-picril hydrazyl radical (DPPH) free radical method was used to determine the antioxidant activity which is based on the determination of the concentration of DPPH at steady state in a methanol solution [5]. According to the study of I. Stoilova et al., the synthetic antioxidant, butylhydroxytoluene (BHT) was used as positive control. The optic density was measured at $518 \mathrm{~nm}$ [6]. The antioxidant activity (AA) was determined using the following formula (2):

$A A \%=100-\{[($ Abs.sample - Abs.empty sample $) \times 100] / A b$ s.control $\}$

\subsection{Determination of Total Phenolic Content}

The total phenolic content was determined using Folin-Ciocalteu reagents [7]. The assay was done by $1 \mathrm{ml}$ of extract or standard solutions $(0-500 \mathrm{mg} / \mathrm{l})$ were added to $10 \mathrm{ml}$ deionized water and 1.0 $\mathrm{ml}$ of Folin-Ciocalteu phenol reagents. After 5 minutes, $2.0 \mathrm{ml}$ of $20 \%$ sodium carbonate was added to the mixture and kept in dark condition for 1 hour. The absorbances of the samples were measured at $750 \mathrm{~nm}$.

\subsection{Validation of Data using F-test}

The F-value from the calculation of ANOVA was compared with the F-value from the table to determine either the null hypothesis was accepted or rejected. If the value of $F_{\text {calc }}$ larger than $\mathrm{F}_{\text {table, then }}$ the null hypothesis is accepted. This means that the $\mathrm{F}_{\text {calc }}$ falls within the accepted region in the $\mathrm{F}$ distribution curve which is shown in Figure 2. The accepted region is lies on the left hand side of the $F_{\alpha}$ and the rejected region lies on the right hand side. The $\alpha$ value is the error value and if the F-value lies in this region, the equation chosen is not significant.

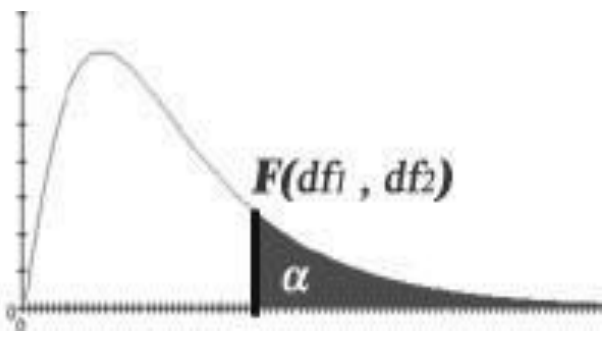

Figure 2 The F-value distribution curve

\subsection{RESULTS AND DISCUSSION}

\subsection{Statistical Analysis}

The effect of temperature and pressure on the extraction of oil yield, antioxidant activity and total phenolic content were analyzed using Statistica 8.0 based on the Box-Behken experiment design.

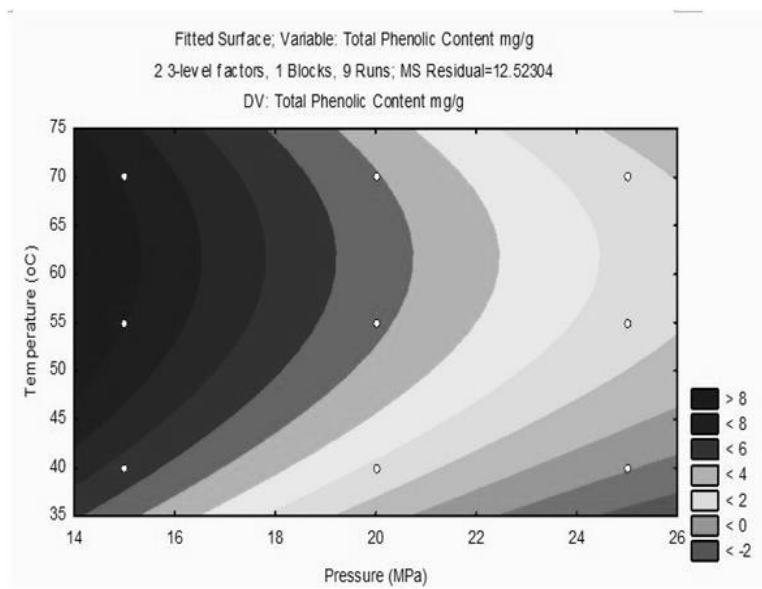

Figure 3 Contour plot of the $\mathrm{SC}-\mathrm{CO}_{2}$ extraction on oil yield as related to temperature and pressure 


\subsection{Effect of Temperature and Pressure on the Oil Yield}

Figure 3 shows the contour plot of the relationship between temperature and pressure to the extraction of oil yield. The highest oil yield obtained when extraction process was performed at the operating pressure of $24 \mathrm{MPa}$ while temperature was $65^{\circ} \mathrm{C}$ and above. However, the increase of temperature will decrease the oil yield while at higher pressure; the oil yield was increased when the temperature was increased. This phenomenon is due to the resistance of mass transfer in the matrices [4]. The contour plot also shows that the oil yield was increased when the increasing of operating pressure due to the increase of the solvating power of carbon dioxide.

\subsection{Effect of Temperature and Pressure on Antioxidant Activity}

The RSM also used to evaluate the effect of temperature and pressure on the antioxidant activity in the virgin coconut oil. As shown in Figure 4, the highest antioxidant activity was obtained when the extraction of virgin coconut oil was performed at the pressure of $18 \mathrm{MPa}$ to $22 \mathrm{MPa}$ and temperature of $40^{\circ} \mathrm{C}$ to $55^{\circ} \mathrm{C}$. Temperature is one of the most significant factors affecting antioxidant activity [8]. When increasing the extraction temperature, the least antioxdant activity was attained because the easily oxidisable antioxidants show a decrease antioxidant activity with increasing temperature at a slower rate than the less oxidisable ones [9].

\subsection{Effect of Temperature and Pressure on Total Phenolic Content}

The total phenolic content was increased with the increasing of extraction temperature as shown in Figure 5. The highest total phenolic content as indicated in the contour plot was more than 8 when the extraction of virgin coconut oil was performed at a temperature and pressure of $55^{\circ} \mathrm{C}$ to $70^{\circ} \mathrm{C}$ and $15 \mathrm{MPa}$ respectively. Studies have shown that the solubility of phenolic increases with the increasing of operating pressure resulting an increase in phenolic yield [10-13].

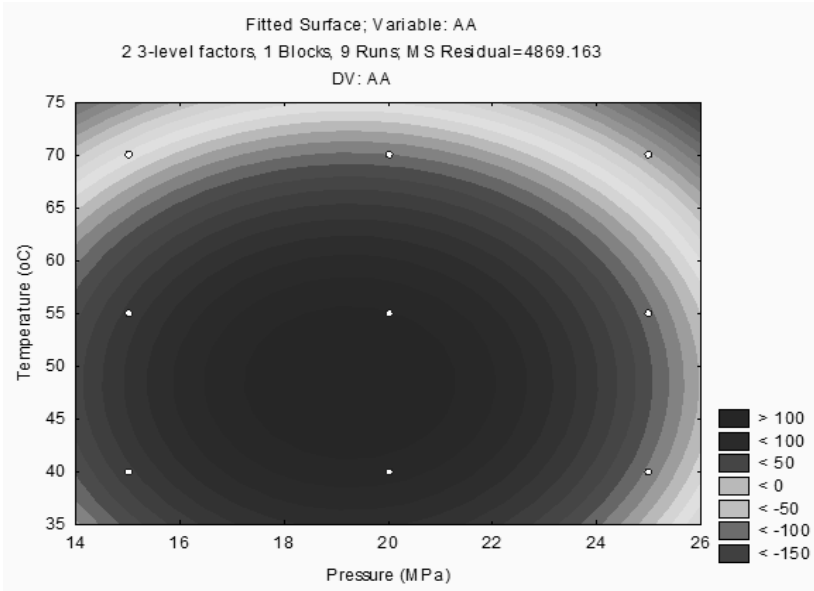

Figure 4 Contour plot of the relationship between operating temperature and pressure with antioxidant activity

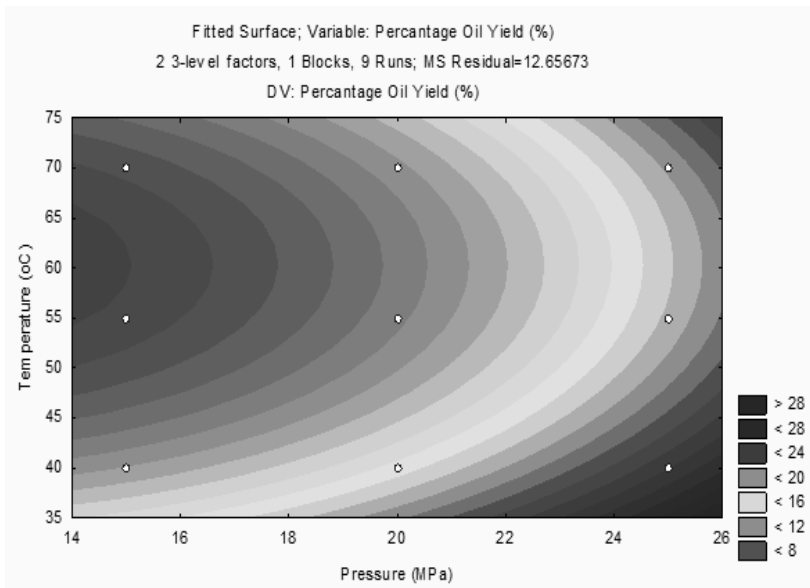

Figure 5 Effect of temperature and pressure on total phenolic content

\subsection{Pareto Chart}

The Pareto chart shows the most influential variable that can affect the extraction process. The variable that has the highest impact on the extraction process is located on the top of the chart and the variable that has the least impact on the extraction process will be located at the bottom of the chart.

As shown in Figure 6, the most influential variable in the extraction process of virgin coconut oil was the operating pressure in linear term with degree value of 4.091 . This is because increasing the operating pressure will increase the solubility of the material and thus give the highest oil yield. Furthermore, extraction process performed at higher pressure will reduce the viscosity of the supercritical fluid and avoid the surface tension limitation. Hence, this can lower the resistance causing the mass transfer more favorable.

\subsection{Analysis of Variance (ANOVA)}

Analysis of variance was used to test the significance of the quadratic model by applying the F-test measurement with $90 \%$ confidence level. F-value is a measurement of variance of data about the mean, based on the ratio of mean square of group variance due to error. ANOVA can be determined by comparing the F-value of the statistical models with the experimental data. The quadratic models of the extraction of oil yield, antioxidant activity and total phenolic content were shown as below:

Oil Yield:

$\mathrm{Y}_{1}=65.509-1.326 \mathrm{X}+0.063 \mathrm{X}^{2}-1.78 \mathrm{Y}-0.015 \mathrm{Y}^{2}$

Antioxidant activity:

$\mathrm{Y}_{2}=-1379.223+103.985 \mathrm{X}-2.670 \mathrm{X}_{2}+20.605 \mathrm{Y}-0.213 \mathrm{Y}_{2}$

Total Phenolic Content:

$Y_{3}=-1308.93+101.12 X-2.62 X^{2}+19.52 Y-0.20 Y^{2}$ 


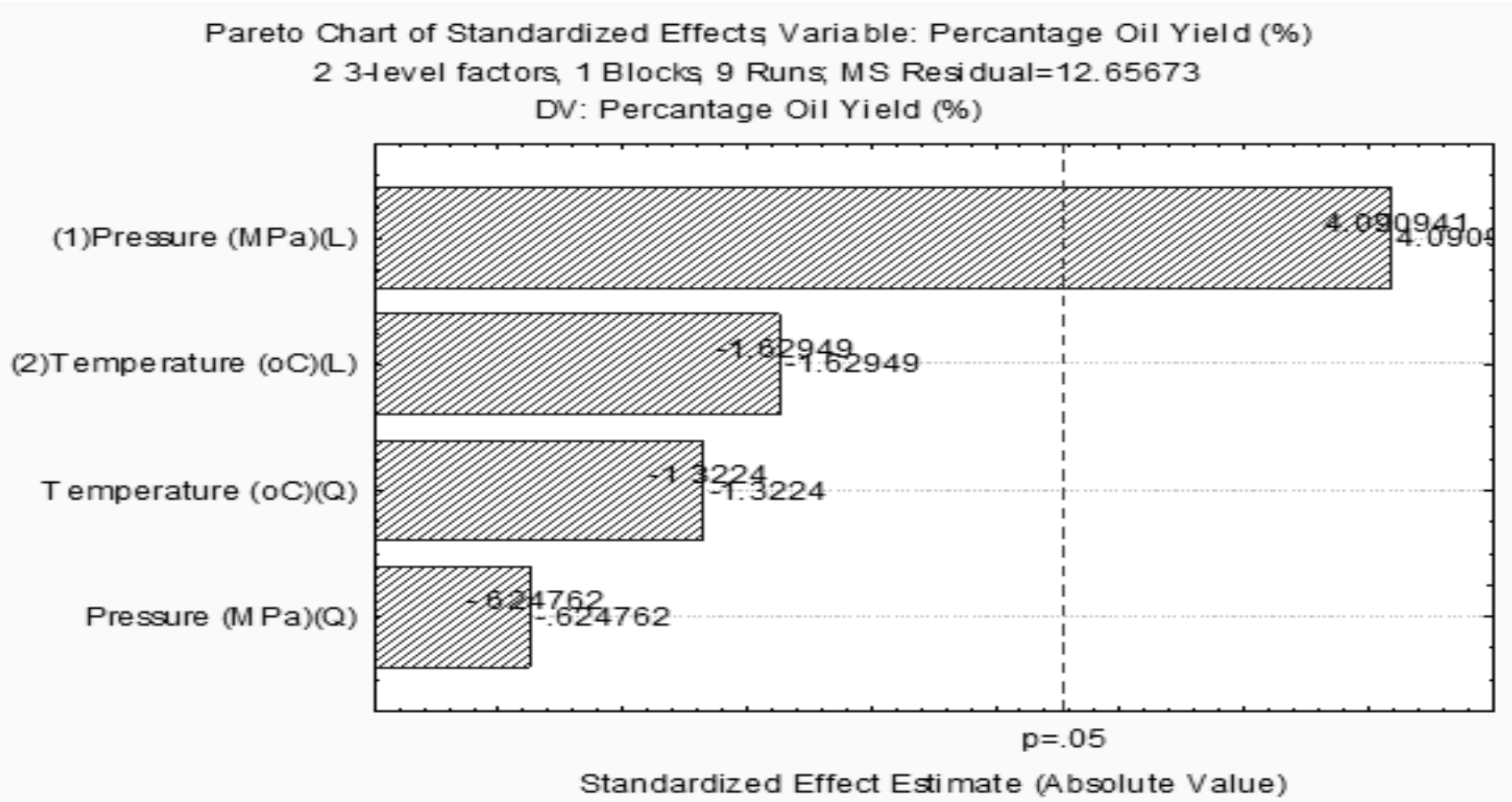

Figure 6 Pareto chart of the most influential variable on the extraction of virgin coconut oil

Table 2 Analysis of variance for oil yield, antioxidant activity and total phenolic content

\begin{tabular}{|c|c|c|c|c|c|c|c|}
\hline Responses & $\begin{array}{l}\text { Source of } \\
\text { Variation }\end{array}$ & Sum of Square & d.f & $\begin{array}{c}\text { Mean Square, } \\
\text { MS }\end{array}$ & $\mathbf{F}_{\text {table }}$ & $\mathbf{F}_{\text {calculated }}$ & $\begin{array}{c}\text { Regession } \\
\left(\mathbf{R}^{2}\right)\end{array}$ \\
\hline \multirow[t]{3}{*}{ Oil Yield } & Due to Regression & 272.5006 & 4 & 68.1252 & \multirow{3}{*}{$\begin{array}{c}\mathrm{F}_{(4),(4)}=4.1072 \\
(\text { at } \mathrm{P}=0.01)\end{array}$} & \multirow[t]{3}{*}{5.382} & \multirow[t]{3}{*}{0.8433} \\
\hline & Residue & 50.6269 & 4 & 12.6567 & & & \\
\hline & Total & 323.1277 & 8 & & & & \\
\hline \multirow{3}{*}{$\begin{array}{l}\text { Antioxidant } \\
\text { Activity }\end{array}$} & Due to Regression & 26588.99 & 4 & 6647.25 & \multirow{3}{*}{$\begin{array}{c}\mathrm{F}_{(4),(4)}=4.1072 \\
\quad \text { at } \mathrm{P}=0.01)\end{array}$} & \multirow[t]{3}{*}{1.365} & \multirow[t]{3}{*}{0.5722} \\
\hline & Residue & 19476.65 & 4 & 4869.16 & & & \\
\hline & Total & 46065.64 & 8 & & & & \\
\hline \multirow{3}{*}{$\begin{array}{l}\text { Total Phenolic } \\
\text { Content }\end{array}$} & Due to Regression & 75.7420 & 4 & 18.9355 & \multirow{3}{*}{$\begin{array}{c}\mathrm{F}_{(4),(4)}=4.1072 \\
\quad(\text { at } \mathrm{P}=0.01)\end{array}$} & \multirow[t]{3}{*}{0.3431} & \multirow[t]{3}{*}{0.60192} \\
\hline & Residue & 50.0922 & 4 & 12.5230 & & & \\
\hline & Total & 125.8342 & 8 & & & & \\
\hline
\end{tabular}

Table 2 shows the analysis of variance for oil yield, antioxidant activity and total phenolic content. The $\mathrm{F}_{\text {table }}$ of the oil yield was 4.1072 while the $\mathrm{F}_{\text {calculated was }} 5.3852$ which is larger than

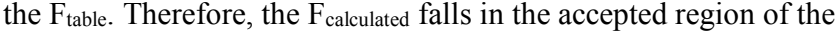
F distribution curve and this shows that the quadratic model is significant and the null hypothesis is accepted. Meanwhile, the value of $\mathrm{F}_{\text {table }}$ for the antioxidant activity was 4.1072 while the $F_{\text {calculated }}$ is smaller than $F_{\text {table }}$ which is 1.365 . Hence, the $F_{\text {calculated }}$ falls in the rejected region of the $\mathrm{F}$ distribution curve and this shows that the statistical model is not significant and the null hypothesis is rejected. Furthermore, the ANOVA analysis of total phenolic content, the $\mathrm{F}_{\text {table }}$ was 4.1072 while the $\mathrm{F}_{\text {calculated }}$ is 0.3431 , which is smaller than the $\mathrm{F}_{\text {table. }}$ So, the $\mathrm{F}_{\text {calculated }}$ falls in the rejected region of the F distribution curve and this also shows that the model is not significant and the null hypothesis is rejected.

\subsection{CONCLUSION}

The extraction of virgin coconut oil (VCO) was performed using supercritical carbon dioxide $\left(\mathrm{SC}-\mathrm{CO}_{2}\right)$ at various temperature and pressure. The use of $\mathrm{SC}-\mathrm{CO}_{2}$ extraction technique extracts more than $14 \%$ on average with shorter extraction time at a fix constant flow rate. The extracted VCO was analyzed using response surface methodology (RSM) to evaluate the effect of pressure and temperature on the oil yield, antioxidant activity and total phenolic content. The Pareto chart showed that the most influential parameter is operating pressure in order to obtain the optimum oil yield. The optimum condition for the extraction of VCO was obtained through statistical study which is pressure $20 \mathrm{MPa}$ and temperature $47^{\circ} \mathrm{C}$ giving $22.67 \%$ oil yield.

\section{Acknowledgement}

The authors gratefully acknowledge the Centre of Lipid Engineering and Applied Research (CLEAR) and also Universiti Teknologi Malaysia, Johor for the laboratory experiment and instruments provided. Acknowledgement is also extended to Ministry of Higher Education (MOHE) provided the grant of ERGS (Vot 4L037) for the financial support. 


\section{References}

[1] Wahyu, B.S. 2010. Extraction and Solubility Studied of Medium Chain Triglycerides from Coconut (Cocos nucifera) Flesh Using Supercritical Carbon Dioxide. Thesis of Doctor of Philosophy. Universiti Sains Malaysia.

[2] Marten, B., M. Pfeuffer, and J. Schrezenmeir. 2006. Medium-chain triglyceride (review). International Dairy Journal. 16: 1374-1382.

[3] Nevin, K.G., and T. Rajamohan. 2005. Virgin Coconut Oil Supplemented Diet Increases the Antioxidant Status in Rats. Food Chemistry. 99: 260 266.

[4] Wahyu, B. S., A.B., Nik, C. Y. Azizi, and A. K. Omar. 2007. MediumChain Triglycerides Rich Oil Extraction using Supercritical Carbon Dioxide. International Conference on Chemical Sciences.

[5] Ramamoorthy, P. K., and B. Awang. 2007. Antioxidant Activity, Total Phenolic Content of Morinda Citrifolia Fruit Extracts from Various Extraction Process. Journal of Engineering Science and Technology. 2(1): 70-80.

[6] Stoilova, I., A. Krastanov, A. Stoyanova, P. Denev, and S. Gargova. 2007. Antioxidant Activity of a Ginger Extract (Zingiber officinale). Food Chemistry. 102(3): 764-770.

[7] Singleton, V. L., and J. A. Rossi. 1965. Colorimetry of American Journal of Enology and Viticulture. 16: 144-158. Total Phenolics With Phosphomolybdic-Phosphotungstic Acid Reagents.
[8] Reblova, Z., J. Fisnar, D. Tichovska, M. Dolezal, and Joudalova K. 2012. Effect of Temperature and Oil Composition on the Ability of Phenolic Acids to Protect Naturally Present $\alpha$-Tocopherol during the Heating Of Plant Oils. Czech Journal of Food Sciences. 30(4): 351-357.

[9] Reblova, Z. 2012. Effect of Temperature on the Antioxidant Activity of Phenolic Acids. Czech Journal of Food Sciences. 30(2): 171-177.

[10] Murga, R., M. T. Sanz, S. Beltran, and J. L. Cabezas. 2002. Solubility of Some Phenolic Compounds Contained in Grape Seeds, In Supercritical Carbon Dioxide. Journal of Supercritical Fluids. 23: 113-121.

[11] Murga, R., M. T. Sanz, S. Beltran, and J. L. Cabezas. 2003. Solubility of Three Hydroxycinnamic Acids in Supercritical Carbon Dioxide. Journal of Supercritical Fluids. 27: 239-245.

[12] Adil, I. H., H. I. Cetin, M. E. Yener, and A. Bayindirli. 2007. Subcritical (carbon dioxide + ethanol) Extraction of Polyphenols From Apple an Peach Pomaces, and Determination of the Antioxidant Activites of the Extracts. Journal of Supercritical Fluids. 43: 55-63.

[13] Adil, I. H., H. I. Cetin, M. E. Yener, and A. Bayindirli. 2008. Extraction of Total Phenolics from Sour Cherry Pomace by High Pressure Solvent and Subcritical Fluid and Determination of the Antioxidant Activities of the Extracts. Separation Science and Technology. 43: 1091-1110. 